ORIGINAL ARTICLE

\title{
Reliability of ophthalmic accident and emergency referrals: a new role for the emergency nurse practitioner?
}

\author{
D G Ezra, F Mellington, H Cugnoni, M Westcott
}

Emerg Med J 2005;22:696-699. doi: 10.1136/emj.2004.018010

Background and objectives: Annual attendances at the accident and emergency (A\&E) department of St Bartholomew's and The Royal London NHS Trust exceed 100000 people of which $6 \%$ are ophthalmic. This study evaluated the accuracy of eye referrals from A\&E senior house officers (SHOs) and emergency nurse practitioners (ENPs) and the impact any inaccuracies may have had on out of hours work.

Methods: Over a four week period a record of all referrals from the A\&E department was made. The doctor receiving the referral made a note of clinical variables as reported by the referring clinician. When the patient was subsequently reviewed by an ophthalmologist, a record was again made of these findings. Any discrepancies were recorded.

See end of article for authors' affiliations

Correspondence to

D G Ezra, daniel_ezra@

hotmail.com

Accepted for publication 29 September 2004
Results: A total of 67 patients were recruited. ENPs were found to be consistently more accurate than $\mathrm{SHO}$ s in every aspect of the assessment, most notably in visual acuity $(p=0.0029)$, and provisional diagnosis $(p=0.012)$. Furthermore, had the examination findings been accurate, $58 \%$ of all SHO referrals seen after hours would have been triaged to the next available clinic but only $10 \%$ of ENP referrals could have been seen at the next clinic session $(p=0.027)$.

Conclusion: This study found ENPs to be more accurate than A\&E SHOs in history taking, recording visual acuity, describing ocular anatomy, and making provisional diagnoses. A significant reduction in out of hours ophthalmic workload may be achieved in the authors' unit if ENPs were to see all eye emergencies.
A nnual attendances at the accident and emergency (A\&E) department of St Bartholomew's and The Royal London NHS Trust exceed 100000 people. Eye emergencies constitute about $6 \%$ of all new attendances and thus form a significant part of the A\&E workload. Most patients with eye complaints presenting to A\&E are seen by a senior house officer (SHO) or an emergency nurse practitioner (ENP). The challenges posed by the high proportion of eye emergencies for the organisation and training of A\&E departments has been noted. ${ }^{1}$ In recent months, the compliance of junior doctors hours with European working time directives has led to changes in working practices. ${ }^{2}$ Much scrutiny has now been placed on the out of hours emergency cover provided by ophthalmology units.

This study was undertaken to determine the accuracy and reliability of junior A\&E doctors and ENPs in assessing eye emergencies to clarify the appropriateness of referrals and reduce unnecessary out of hours work for the ophthalmology team on call. It is essential that the on-call ophthalmologist is given accurate and reliable information in order to make a decision on whether the patient is to be seen that night or otherwise be safely managed with simple telephone advice or seen the next morning during working hours.

\section{METHODS}

This prospective study was undertaken at the St Bartholomew's and The Royal London Hospitals ophthalmic department which has on-call commitments to both of these hospitals as well as the Homerton University Hospital in east London. The A\&E departments of these hospitals are run by the same clinical teams who rotate between these hospitals. ENPs perform the same role as A\&E SHOs in the minor injuries unit and there is no case selection between the two. A total of 15 ENPs and 26 SHOs participate in the rota across sites at any time. All the SHOs receive the same training and all the ENPs receive the same practitioner training across all sites, although the two groups differ in their respective training.
The A\&E departments are well equipped with a slit lamp, Snellen chart and a wide range of diagnostic and therapeutic ophthalmological agents. Both ENPs and A\&E SHOs use the same equipment.

Over a four week period, a detailed record of all referrals from the A\&E department was made using a standardised pro forma. The doctor receiving the referral made a record of the following variables as reported by the referring clinician: grade of referring clinician, visual acuity, adnexa, conjunctiva, cornea, pupils, iris, fundus, and impression/provisional diagnosis.

When the patient was subsequently reviewed and examined by an ophthalmologist, a record was again made of these findings. Any discrepancy between the two datasets was also noted. When comparing the datasets, the observer was masked to the grade of referring clinician. Where discrepancies occurred in referrals leading to out of hours ophthalmic review, the observer noted whether or not the decision to see the patient after hours would have changed had the information given in the referral been correct.

\section{RESULTS}

A total of 67 patients were recruited and the data were organised according to the grade of the referring clinician: 36 patients were referred by an SHO, 20 patients were referred by an ENP, 5 were referred by a consultant, and 2 by a registrar. The data on consultant and registrar referrals have not been included due to the small numbers. Four datasets were excluded from the study due to incomplete data collection or illegible recording. A comparison of the main examination findings for ENPs and SHOs is summarised in table 1.

The most notable discrepancy between ENPs and SHOs in examination reliability was found to lie in accuracy recording

Abbreviations: A\&E, accident and emergency; ENP, emergency nurse practitioner; $\mathrm{SHO}$, senior house officer 
Table 1 Distribution of errors made. Values are $\mathrm{n}(\%)$

\begin{tabular}{|c|c|c|c|c|c|}
\hline & \multicolumn{2}{|c|}{ Senior house officer } & \multicolumn{2}{|c|}{ Emergency nurse practitioner } & \multirow{2}{*}{$\begin{array}{l}\text { Statistical difference } \\
\text { (p value) }\end{array}$} \\
\hline & Accurate & Inaccurate & Accurate & Inaccurate & \\
\hline Visual acuity uncorrected & $19(30)$ & $45(70)$ & $24(62)$ & $15(38)$ & $0.0029^{*}$ \\
\hline History & $33(92)$ & $3(8)$ & $20(100)$ & $0(0)$ & $0.52 \dagger$ \\
\hline Adnexa & $36(100)$ & $0(0)$ & $20(100)$ & $0(0)$ & 1.0 \\
\hline Conjunctiva & $27(80)$ & $7(20)$ & $20(100)$ & $0(0)$ & 0.206 \\
\hline Cornea/fluorescein & $26(78)$ & $8(22)$ & $19(95)$ & $1(5)$ & 0.16 \\
\hline Pupil & $36(100)$ & $0(0)$ & $20(100)$ & $0(0)$ & 1.0 \\
\hline Iris & $32(89)$ & $4(11)$ & $20(100)$ & $0(0)$ & 0.32 \\
\hline Fundus & $3(38)$ & $5(62)$ & Not done & & \\
\hline $\begin{array}{l}\text { Provisional diagnosis/ } \\
\text { impression }\end{array}$ & $13(36)$ & $23(64)$ & $15(75)$ & $5(25)$ & $0.012^{*}$ \\
\hline
\end{tabular}

of visual acuity (VA). Only $30 \%$ of VAs tested by the SHOs were found to be accurate compared with $62 \%$ of VAs recorded by ENPs $\left(p=0.0029, \chi^{2}\right)$. The degree of error as represented by the number of lines of Snellen chart inaccuracy is demonstrated in fig 1 . Inverted Snellen fractions were not designated as inaccurate but considered as annotation errors only.

Variation in VA error with the acuity recorded by the ophthalmologist for SHOs and ENPs is illustrated in figures 2 and 3, respectively. These data show that the errors which both groups tended to make was one of underestimation. ENPs tended to be far more accurate than SHOs at recording VAs. The ENPs' errors were consistently of slight underestimation with a mean underestimation of 0.56 Snellen lines (95\% confidence interval -0.8 to -0.3 ). Spearman's rank correlation $(\rho)$ was calculated at 0.7288 . In contrast SHOs tended to underestimate higher VAs by a much greater amount, and also to overestimate low VAs considerably $(\rho=0.44)$.

Other differences in reliability lay in examination of the cornea and conjunctiva: $20 \%$ of all SHO referrals contained errors in examination of the conjunctiva and $22 \%$ of SHO referrals involved corneal examination error. Further analysis of the patients' notes revealed that half of these errors were consistently due to basic anatomical confusion between the cornea, iris, and conjunctiva (table 2). No ENP referral contained these errors.

A marked discrepancy in accuracy of provisional diagnosis was also evident between the two groups. Only $36 \%$ of SHO provisional diagnoses were correct compared with $75 \%$ in the ENP group $\left(p=0.012, \chi^{2}\right)$.

Many of the emergency referrals were seen after hours, either on a weekend or at night. In these cases the examining ophthalmologist recorded whether any inaccuracies conveyed

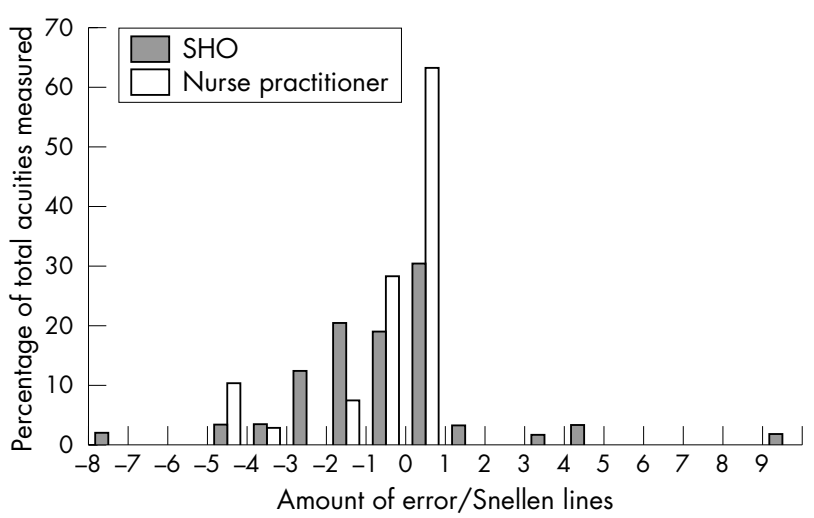

Figure 1 Distribution of visual acuity error.

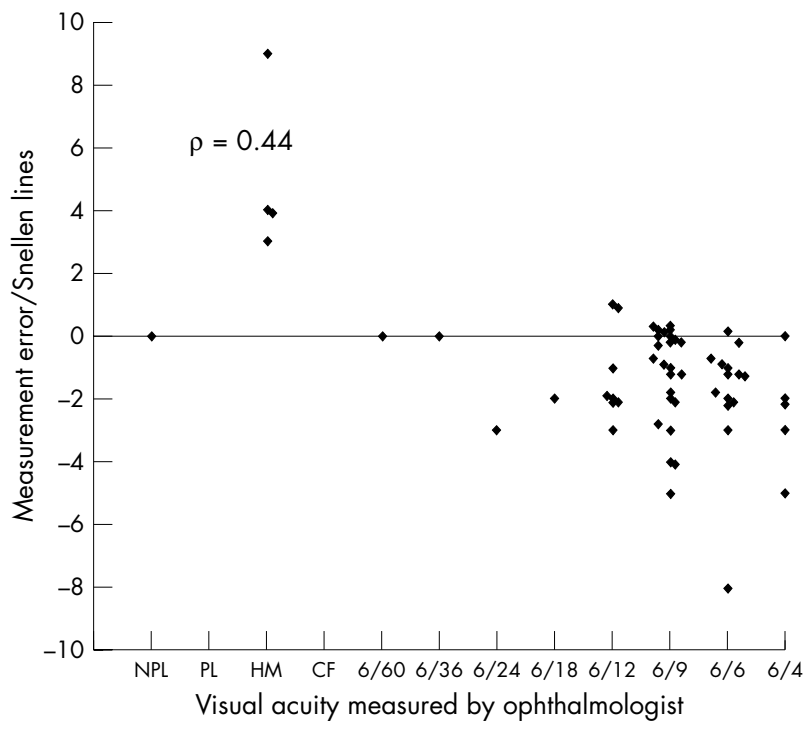

Figure 2 Comparison of accident and emergency senior house officer and ophthalmologist visual acuity recordings.

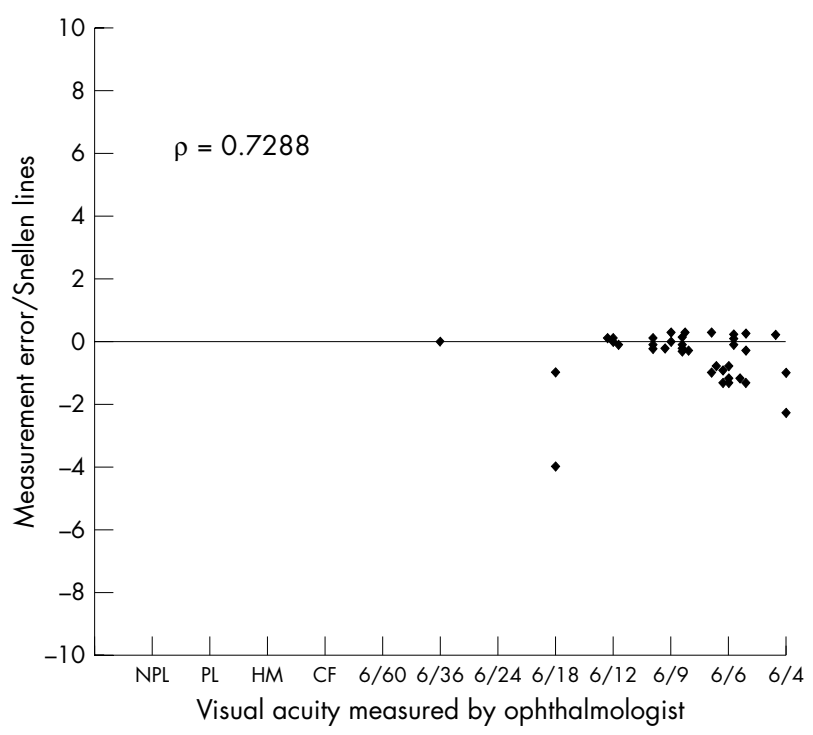

Figure 3 Comparison of emergency nurse practitioner and ophthalmologist visual acuity recordings. 


\begin{tabular}{lll}
$\begin{array}{l}\text { Table } 2 \text { Comparison of anatomical confusion. } \\
\text { Values are } \mathrm{n}(\%)\end{array}$ \\
\hline & $\begin{array}{l}\text { Senior house } \\
\text { officer }\end{array}$ & $\begin{array}{l}\text { Emergency nurse } \\
\text { practitioner }\end{array}$ \\
\hline Cornea-conjunctiva & $4(11)$ & $0(0)$ \\
Cornea-iris & $4(11)$ & $0(0)$ \\
\hline
\end{tabular}

in the referral led to the ophthalmologist on call to make a decision to see urgently out of hours a patient who would otherwise have been safely seen in clinic the next day. These results are listed in table 3; $58 \%$ of all SHO referrals seen after hours would have been triaged to the next available clinic if the examination findings were accurate whereas only $10 \%$ of ENP referrals could have been seen at the next clinic session $(p=0.027$, Fisher's exact test $)$.

\section{DISCUSSION}

Our results illustrate a poor reliability of examination findings by A\&E SHOs. The most notable errors lay in measurement of VA and a deficiency in anatomical vocabulary in describing the cornea, conjunctiva, and iris. In contrast, the quality of examination and assessment by ENPs was high with only half the error rate in VA of the SHO group. In our study ENPs have been found to be to be consistently more accurate than A\&E SHOs in history taking, recording VA, describing ocular anatomy, provisional diagnoses, and, consequently, making referrals.

The problems encountered by A\&E SHOs in assessing ophthalmic casualty patients is cause for some concern. Previous studies that have assessed omissions in ophthalmic assessment by A\&E SHOs found highly significant omissions such VA, history taking and fluorescein corneal instillation. ${ }^{34}$ However, these studies focused on the absence of examination steps rather than the reliability of the examination that had been performed.

The reason for poor performance of A\&E SHO ophthalmic examination is multifactorial. We must consider the possible impact of increasing marginalisation of ophthalmology at medical school following the recent reorganisation of medical education. Furthermore, specific ophthalmic training for SHOs is extremely variable. A recent survey in the UK found that $69 \%$ of A\&E SHOs nationwide had little or no confidence in dealing with ophthalmic cases, and $26 \%$ received no training in ophthalmic emergencies. ${ }^{5}$ Finally, educational rather than professional discrepancies must also be considered. Ophthalmic training differs between the two groups and may also account for the superior performance of the ENP group.

Recent years have seen the introduction of nurse practitioner grades who are performing a similar role to A\&E SHOs. ENPs have had a role in managing ophthalmic A\&E patients for some time ${ }^{6}$ and are proving to be extremely valued and clinically competent members of the healthcare team. ${ }^{78}$ Only a few studies on ENP effectiveness have been published and we note important work by Sakr et al ${ }^{9}$ showing no significant difference between SHOs and ENPs in assessment and treatment of patients in a single minor injuries unit, although none of these patients had ophthalmic problems. However, many comparative studies focus on patient satisfaction and transit times rather than objective clinical endpoints. ${ }^{10}$ Nurse practitioners have also been shown to have a superior standard of documentation than SHOs. ${ }^{11}$

In view of the future proposed extension of the European Working Time Directive (EWTD) to include doctors in training, it more important than ever to minimise unnecessary out of hours work for the on-call ophthalmologist. Poor

\begin{tabular}{|c|c|c|}
\hline & $\begin{array}{l}\text { Senior house } \\
\text { officer }\end{array}$ & $\begin{array}{l}\text { Emergency nurse } \\
\text { practitioner }\end{array}$ \\
\hline $\begin{array}{l}\text { No delay } \\
\text { Delay }\end{array}$ & $\begin{array}{l}11(42) \\
15(58)\end{array}$ & $9(90)$ \\
\hline
\end{tabular}

accuracy of examination findings often leads to a same-day ophthalmic assessment which could otherwise be safely managed with simple telephone advice from the on-call ophthalmologist or safely seen the next morning during working hours in an appropriate clinic with senior support. In the present study $58 \%$ of all SHO referrals that led to out of hours consultations could have been seen the next day compared with only $10 \%$ of ENP referrals. This represents a very large proportion of out of hours workload which could be avoided.

Our study has some limitations that must be identified. The study reflects the practice of our unit only. Both ENP and SHO training varies widely among departments at different hospitals and further research is needed to investigate whether the findings outlined here are reflected elsewhere. Furthermore, although the observer comparing the A\&E datasets with those of the ophthalmologist was masked to the grade of referring clinician, the ophthalmologist receiving the referral was not. This is because the ophthalmologist would have been contacted by the A\&E clinician and would have seen the accompanying medical notes, as is normal practice when receiving a referral. Despite this potential for bias, we believe that the effects would have been minimal as one would have expected the bias to favour reliability of SHOs, when in fact the results still demonstrate significantly higher concordance with ENPs rather than SHOs.

At present, the SHOs and ENPs at St Bartholomew's and The London NHS Trust differ in their ophthalmic training: A\&E SHOs attend a short seminar in the first week at the A\&E department whereas ENPs are encouraged to spend several mornings observing in an eye outpatient clinic. We advocate a combined approach with the emphasis on the most basic skills such as history taking and examination, concentrating particularly on VA with a revision of basic ocular anatomy.

It has been suggested that "the implementation of the EWTD and reducing the hours of doctors in training may require innovative approaches to how services are staffed". This may include "developing new healthcare practitioner roles to take on work currently carried out by doctors" ${ }^{12}$ Expanding the role of the ENP may be part of the solution.

\section{Authors' affiliations}

D G Ezra, F Mellington, H Cugnoni, M Westcott, Departments of Ophthalmology and Accident \& Emergency Medicine, St Bartholomew's and the Royal London NHS Trust, London, UK

Competing interests: none declared

\section{REFERENCES}

1 Bhopal RS, Parkin DW, Gillie RF, et al. Pattern of ophthalmological accidents and emergencies presenting to hospitals. J Epidemiol Community Health 1993;47:382-7.

2 Department of Health. Guidance on working patterns for junior doctors. London: DoH, November, 2002.

3 Flitcroft DI, Westcott M, Wormald R, et al. Who should see eye casualties? A comparison of eye care in an accident and emergency department with a dedicated eye casualty. J Accid Emerg Med 1995; 12:23-7.

4 Clancy MJ, Hulbert M. A study of the eye care provided by an accident and emergency department. Arch Emerg Med 1991;8:122-4. 
5 Tan MM, Driscoll PA, Marsden JE. Management of eye emergencies in the accident emergency department by senior house officers: a national survey. $J$ Accid Emerg Med 1997; 14:157-8.

6 Jones NP, Hayward JM, Khaw PT, et al. Function of an ophthalmic "accident and emergency" department: results of a six month survey. BMJ 1986;292:188-91.

7 Baneriee S, Beatty S, Tyagi A, et al. The role of ophthalmic triage and the nurse practitioner in an eye-dedicated casualty department. Eye 1998;12:880-2.

8 Hango B, McGalliard JN, Hughes A. The role of nurse practitioners in a primary care eye clinic. Accid Emerg Nurs 2000;8:42-5.
9 Sakr M, Angus J, Perrin J, et al. Care of minor injuries by emergency nurse practitioners or junior doctors: a randomised control trial. Lancet 1999;354:1321-6.

10 Dealey C. Emergency nurse practitioners: should the role be developed? Br J Nurs 2002;10:1458-68.

11 Cooper MA, Lindsay GM, Kinn S, et al. Evaluating emergency nurse practitioner services: a randomised control trial. J Adv Nurs 2002;40:721-30

12 The European Working Time Directive. www.doh.gov.uk/working time/ back.html (accessed March 2004).

\section{bmjupdates+}

bmjupdates+ is a unique and free alerting service, designed to keep you up to date with the medical literature that is truly important to your practice.

bmjupdates+ will alert you to important new research and will provide you with the best new evidence concerning important advances in health care, tailored to your medical interests and time demands.

Where does the information come from?

bmjupdates+ applies an expert critical appraisal filter to over 100 top medical journals A panel of over 2000 physicians find the few 'must read' studies for each area of clinical interest

Sign up to receive your tailored email alerts, searching access and more...

www.bmjupdates.com 